\title{
Cost minimization in treatment of adult degenerative scoliosis
}

\author{
Omar M. Uddin, BA, ${ }^{1}$ Raqeeb Haque, MD, ${ }^{1}$ Patrick A. Sugrue, MD, ${ }^{1}$ Yousef M. Ahmed, MD, ${ }^{1}$ \\ Tarek Y. El Ahmadieh, MD, ${ }^{1}$ Joel M. Press, MD, ${ }^{2}$ Tyler Koski, MD, ${ }^{1}$ and Richard G. Fessler, MD, PhD ${ }^{3}$
} 1Department of Neurological Surgery, Northwestern University Feinberg School of Medicine; ${ }^{2}$ Rehabilitation Institute of Chicago;
and ${ }^{3}$ University Neurosurgery, Rush University Medical Center, Chicago, Illinois

OBJECT Back pain is an increasing concern for the aging population. This study aims to evaluate if minimally invasive surgery presents cost-minimization benefits compared with open surgery in treating adult degenerative scoliosis.

METHODS Seventy-one patients with adult degenerative scoliosis received 2-stage, multilevel surgical correction through either a minimally invasive spine surgery (MIS) approach with posterior instrumentation $(n=38)$ or an open midline (Open) approach $(n=33)$. Costs were derived from hospital and rehabilitation charges. Length of stay, blood loss, and radiographic outcomes were obtained from electronic medical records. Functional outcomes were measured with Oswestry Disability Index (ODI) and visual analog scale (VAS) surveys.

RESULTS Patients in both cohorts were similar in age $\left(\mathrm{Age}_{\mathrm{MIS}}=65.68 \mathrm{yrs}, \mathrm{Age}_{\mathrm{Open}}=63.58 \mathrm{yrs}, \mathrm{p}=0.28\right)$. The mean follow-up was 18.16 months and 21.82 months for the MIS and Open cohorts, respectively $(p=0.34)$. MIS and Open cohorts had an average of 4.37 and 7.61 levels of fusion, respectively $(p<0.01)$. Total inpatient charges were lower for the MIS cohort $(\$ 269,807$ vs $\$ 391,889, p<0.01)$, and outpatient rehabilitation charges were similar $(\$ 41,072$ vs $\$ 49,272$, $p=0.48)$. MIS patients experienced reduced length of hospital stay $(7.03$ days vs 14.88 days, $p<0.01)$ and estimated blood loss (EBL) $\left(E \mathrm{BL}_{\mathrm{MIS}}=470.26 \mathrm{ml}, \mathrm{EBL}_{\text {Open }}=2872.73 \mathrm{ml}, \mathrm{p}<0.01\right)$. Baseline ODI scores were lower in the MIS cohort (40.03 vs 48.04, $p=0.03$ ), and the cohorts experienced similar 1-year improvement $\left(\Delta O D I_{M I S}=-15.98, \Delta \mathrm{ODI}_{\text {Open }}=\right.$ $-21.96, p=0.25)$. Baseline VAS scores were similar $\left(\operatorname{VAS}_{\mathrm{MIS}}=6.56, \mathrm{VAS}_{\text {Open }}=7.10, p=0.32\right)$, but MIS patients experienced less reduction after 1 year $\left(\Delta \mathrm{VAS}_{\mathrm{MIS}}=-3.36, \Delta \mathrm{VAS}_{\text {Open }}=-4.73, p=0.04\right)$. Preoperative sagittal vertical axis (SVA) were comparable (preoperative SVA $A_{\text {MIS }}=63.47 \mathrm{~mm}$, preoperative SVA ${ }_{\text {open }}=71.3 \mathrm{~mm}, p=0.60$ ), but MIS patients had larger postoperative SVA (postoperative SVA $\mathrm{MIS}=51.17 \mathrm{~mm}$, postoperative SVA $\mathrm{Spen}=28.17 \mathrm{~mm}, \mathrm{p}=0.03$ ).

CONCLUSIONS Minimally invasive surgery demonstrated reduced costs, blood loss, and hospital stays, whereas open surgery exhibited greater improvement in VAS scores, deformity correction, and sagittal balance. Additional studies with more patients and longer follow-up will determine if MIS provides cost-minimization opportunities for treatment of adult degenerative scoliosis.

http://thejns.org/doi/abs/10.3171/2015.3.SPINE14560

KEY WORDS adult degenerative scoliosis; minimally invasive spine surgery; cost effectiveness; cost benefit; adult spinal deformity

$\mathrm{C}$ HRONIC lower back pain due to degenerative spine disease is an increasing concern in the aging US population and imposes a large economic burden on society. The prevalence of adult scoliosis has been reported to range between $1.4 \%$ and $32 \%$ in the general US population and to be nearly $68 \%$ in the elderly population. ${ }^{6,20} \mathrm{In}$ the last decade, the Medicare costs of treating adult spinal deformity (ASD) have increased more than 16-fold, from $\$ 56$ million to more than $\$ 958$ million. ${ }^{13}$ ASD can be a se- verely debilitating ailment and is mainly characterized by claudication, radiculopathy, and disabling back pain. ${ }^{15}$ Older adults often experience greater disability and back and leg pain due to scoliosis compared with younger adults. ${ }^{21}$

First-line treatment of ASD includes conservative strategies such as regular exercise, physical therapy, and antiinflammatory medications.,22 For conditions that are refractory to conservative medical management, surgical correction is used. The decision to undergo surgery in the

ABBREVIATIONS ASD = adult spinal deformity; BMI = body mass index; DVT = deep vein thrombosis; EBL = estimated blood loss; ISSG = International Spine Study Group; LLIF = lateral lumbar interbody fusion; MIS = minimally invasive spine surgery; ODI = Oswestry Disability Index; PI-LL = pelvic incidence-lumbar lordosis; PJK = proximal junctional kyphosis; SVA = sagittal vertical axis; TLIF = transforaminal lumbar interbody fusion; VAS = visual analog scale.

SUBMITTED June 5, 2014. ACCEPTED March 11, 2015.

INCLUDE WHEN CITING Published online August 28, 2015; DOI: 10.3171/2015.3.SPINE14560. 
elderly is influenced primarily by the intensity of pain, quality of life, and risk to the patient. ${ }^{4}$

Options for surgical treatment of degenerative scoliosis comprise traditional open surgery or minimally invasive spine surgery (MIS). The traditional open-surgery approach involves an open-posterior only or an anterior/ posterior correction, whereas the MIS approach involves a less invasive lateral lumbar interbody fusion (LLIF) and/ or transforaminal lumbar interbody fusion (TLIF) and percutaneous posterior instrumentation. ${ }^{3,15}$ Open surgery has been shown to be an effective treatment for adult degenerative scoliosis, but there is a significant risk of complications, including a $25 \%-80 \%$ risk of excessive blood loss and infection and a $40 \%$ risk of incisional pain, abdominal hernia, and/or vascular injury. . $^{5,11,15,16}$

In recent years, the MIS approach has become an accepted method to treat numerous spinal pathologies due to the reduced soft-tissue dissection required and the decreased blood loss and length of hospital stay.,10,17 Initially reported by Anand et al. in 2008, MIS techniques were also used to address adult degenerative scoliosis. Long-term clinical follow-up has revealed significant correction of ASD with low pseudarthrosis rates, improved functional and radiographic outcomes, and decreased morbidity. ${ }^{2,3}$

The treatment options for diseases of the spine must be both efficacious and cost effective. To date, studies have compared the costs associated with MIS with those associated with open surgery for the treatment of lumbar stenosis, low-grade degenerative spondylolisthesis, and disc degeneration. Current literature demonstrates that MIS procedures reduce length of hospital stay, residual events, and total hospital charges for 1- and 2-level surgeries compared with open procedures. ${ }^{12,23,24}$ However, the costs of the surgical treatment of ASD have not been adequately studied, and there have been no published data comparing both functional outcomes and costs between MIS and open surgery for adult degenerative scoliosis. ${ }^{13}$

The aim of this study was to conduct a cost-minimization analysis of surgical treatment of adult degenerative scoliosis in which MIS and open surgery were used. Parameters included billed charges, Oswestry Disability Index (ODI) scores, visual analog scale (VAS) scores, and radiographic outcomes.

\section{Methods}

A retrospective analysis of prospectively collected data of patients who had correction of adult degenerative scoliosis at our institution between 2006 and 2012 was conducted. Institutional review board approval was obtained.

\section{Study Population}

This study compared 2 cohorts of patients: those who received MIS and those who received open surgery for staged correction of their adult degenerative scoliosis. Patients in the MIS cohort first received a minimally invasive LLIF/TLIF followed by percutaneous posterior instrumentation. Patients in the Open cohort received traditional open surgery through a posterior midline approach. One neurosurgeon (R.F.) operated on all of the patients in the MIS cohort and another neurosurgeon (T.K.) operated on all of the patients in the Open cohort. The cohorts were matched for age, body mass index (BMI), comorbidities, prior spine surgeries, preoperative sagittal vertical axis (SVA), and preoperative lumbar lordosis. Exclusion criteria included workers' compensation cases, patients receiving disability insurance, and thoracic-level disease.

\section{Costs}

Cost data were obtained from the Northwestern Memorial Hospital and the Rehabilitation Institute of Chicago billing departments. Costs in this study are represented by billed charges. The billing departments were blinded regarding identification of cohorts by using patient encounter codes, which ensured identical billing practices and limited selection bias.

\section{Clinical Outcome Measures}

ODI and VAS scores were prospectively collected preoperatively and postoperatively at 1 month, 3 months, 6 months, 1 year, and 2 years. Complications, length of hospital stay, surgical time, residual events, and EBL were obtained from electronic medical records. Complications noted were dural tears, surgical-site infections, postoperative deep vein thrombosis (DVT), postoperative infections, proximal junctional kyphosis (PJK), migrated cages, displaced grafts, rod fractures, motor deficits, pseudoarthrosis, and the need for revision surgery. Radiographic measurements of lumbar Cobb angle, SVA, lumbar lordosis, pelvic incidence, and pelvic tilt were made preoperatively and postoperatively at 3 months, 6 months, 1 year, and 2 years of follow-up to compare the radiographic correction of scoliosis.

\section{Statistical Analysis}

All numerical parameters for both cohorts were compared and the differences were analyzed using a 2-tailed, unpaired with unequal variance Student's t-test. Statistical significance in this study was $\mathrm{p}<0.05$.

\section{Results \\ Study Population}

A total of 100 consecutive patients were initially selected for the study. Of these, 16 patients were excluded for lack of baseline ODI data, 12 patients were excluded for thoracic-level disease, and 1 patient was excluded for concurrent spinal trauma. Thus, 71 patients were included in the study ( $\mathrm{n}=38$, MIS cohort; $\mathrm{n}=33$, Open cohort). Table 1 summarizes patient demographic data. The mean age \pm SD for all patients was $64.72 \pm 8.21$ years. The mean age for the MIS cohort was $65.68 \pm 8.79$ years and the mean age for the Open cohort was $63.58 \pm 7.45$ years $(\mathrm{p}=0.28)$. The mean BMI was 25.67 and 27.73 for the MIS and Open cohorts, respectively $(\mathrm{p}=0.08)$. On average, patients in the MIS cohort had 2.71 comorbidities and patients in the Open cohort had 2.97 comorbidities $(\mathrm{p}=0.55)$. Patients in the MIS cohort had an average of 0.39 prior spine surgeries whereas patients in the Open cohort had an average of 0.30 prior spine surgeries $(\mathrm{p}=0.58)$. Preoperative ODI 
TABLE 1. Patient demographic data and summary of clinical outcomes

\begin{tabular}{|c|c|c|c|c|c|c|c|}
\hline \multirow[b]{2}{*}{ Variable } & \multicolumn{3}{|c|}{ MIS } & \multicolumn{3}{|c|}{ Open } & \multirow{2}{*}{$\begin{array}{c}p \\
\text { Value }\end{array}$} \\
\hline & Mean & SD & No. of Pts & Mean & SD & No. of Pts & \\
\hline Age (yrs) & 65.68 & 8.79 & 38 & 63.58 & 7.45 & 33 & 0.28 \\
\hline BMI & 25.67 & 3.43 & 37 & 27.73 & 5.68 & 32 & 0.08 \\
\hline Comorbidities & 2.71 & 1.63 & 38 & 2.97 & 1.99 & 33 & 0.55 \\
\hline Prior spine surgeries & 0.39 & 0.89 & 38 & 0.30 & 0.47 & 33 & 0.58 \\
\hline Levels fused & 4.37 & 1.32 & 38 & 7.61 & 1.03 & 33 & $<0.01$ \\
\hline Length of stay (days) ${ }^{*}$ & 7.03 & 3.86 & 38 & 14.88 & 8.20 & 33 & $<0.01$ \\
\hline Length of follow-up (mos) & 18.16 & 13.70 & 38 & 21.82 & 17.61 & 33 & 0.34 \\
\hline EBL during Stage 1 surgery (ml) & 175.53 & 160.82 & 38 & 2410.61 & 1617.81 & 33 & $<0.01$ \\
\hline EBL during Stage 2 surgery (ml) & 800.00 & 1356.32 & 14 & 663.04 & 830.69 & 23 & 0.74 \\
\hline Total EBL (ml) & 470.26 & 865.07 & 38 & 2872.73 & 1468.32 & 33 & $<0.01$ \\
\hline ODI score, baseline & 40.03 & 12.28 & 35 & 48.04 & 14.55 & 25 & 0.03 \\
\hline ODI score, 1 yr & 23.98 & 13.92 & 26 & 25.38 & 19.08 & 26 & 0.76 \\
\hline ODI score, 2 yrs & 29.16 & 17.79 & 21 & 19.75 & 12.92 & 16 & 0.07 \\
\hline Average net change, ODI score (Yr 1 - baseline) & -15.98 & 19.41 & 26 & -21.96 & 17.39 & 25 & 0.25 \\
\hline VAS score back pain, baseline & 6.56 & 1.89 & 33 & 7.10 & 2.11 & 25 & 0.32 \\
\hline VAS score back pain, $1 \mathrm{yr}$ & 3.10 & 2.26 & 25 & 2.51 & 2.46 & 26 & 0.38 \\
\hline VAS score back pain, 2 yrs & 3.68 & 2.62 & 20 & 2.10 & 2.09 & 17 & 0.05 \\
\hline Average net change, VAS score back pain (Yr 1 - baseline) & -3.36 & 2.24 & 25 & -4.73 & 2.40 & 25 & 0.04 \\
\hline VAS score leg pain, baseline & 5.42 & 3.11 & 33 & 5.87 & 3.04 & 25 & 0.59 \\
\hline VAS score leg pain, $1 \mathrm{yr}$ & 2.54 & 2.66 & 26 & 2.69 & 2.85 & 25 & 0.85 \\
\hline VAS score leg pain, 2 yrs & 3.71 & 2.99 & 21 & 1.66 & 2.56 & 17 & 0.03 \\
\hline Average net change, VAS score leg pain (Yr 1 - baseline) & -2.54 & 4.19 & 26 & -3.27 & 3.04 & 24 & 0.48 \\
\hline
\end{tabular}

Pts = patients.

* Also includes any hospital stay related to revision surgery.

scores were 40.03 and 48.04 for patients in the MIS and Open cohorts, respectively ( $p=0.03$ ). Preoperative SVA and lumbar lordosis were not significantly different, but the patients in the Open cohort had a higher mean lumbar Cobb angle (Table 2).

\section{Clinical Outcomes}

The mean lengths of follow-up for the MIS and Open cohorts were 18.16 months and 21.82 months, respectively. Of the 38 patients in the MIS cohort, 26 patients had follow-up at 1 year and 21 patients had follow-up at 2 years. Of the 33 patients in the Open cohort, 26 and 16 patients had follow-up at 1 and 2 years, respectively (Table 1).

Preoperative ODI scores for the MIS and Open cohorts were 40.03 and 48.04 , respectively $(\mathrm{p}=0.03)$. At 1 year follow-up, the mean ODI score was 23.98 for patients in the MIS cohort and 25.38 for patients in the Open cohort $(\mathrm{p}=0.76)$. The mean reduction in the ODI score for the MIS and Open cohorts was -15.98 and -21.96 , respectively; however, this difference was not statistically significant $(\mathrm{p}=0.25)$. VAS back and leg scores were approximately equal at baseline between the groups, but patients in the Open cohort experienced greater reduction in VAS back pain score compared with patients in the MIS cohort $(\mathrm{p}=$ $0.04)$. The reduction in VAS scores for leg pain was similar in both cohorts ( -2.54 MIS vs -3.27 Open, $\mathrm{p}=0.48)$. Table 1 and Fig. 1 summarize ODI and VAS scores.

\section{Radiographic Outcomes}

Improvements in lumbar Cobb angle, lumbar lordosis, and pelvic incidence-lumbar lordosis (PI-LL) were greater in the Open cohort (Fig. 2). The SVA of MIS patients was corrected to approximately $51.17 \mathrm{~mm}$, whereas the SVA of Open patients was corrected to approximately $28.17 \mathrm{~mm}$ $(\mathrm{p}=0.03)$. Preoperative and postoperative radiographic measurements are summarized in Table 2.

\section{Costs}

Patients in the MIS cohort had significantly lower inpatient and total charges (Table 3). The average inpatient charge, including complications and revision surgeries, was $\$ 269,807$ and $\$ 391,889$ for the MIS and Open cohorts, respectively, representing savings of $\$ 122,081$ associated with MIS $(\mathrm{p}<0.01)$. Of the entire study population, 30 patients received outpatient rehabilitation, and the mean total rehabilitation charges were not significantly different between the 2 cohorts $\left(\operatorname{Rehab}_{\mathrm{MIS}}=\$ 41,072.16\right.$; Rehab $_{\mathrm{OPEN}}$ $=\$ 49,272.24, \mathrm{p}=0.48)$. Inflation-adjusted total inpatient costs were $\$ 292,329$ and $\$ 433,620$ for the MIS and Open cohorts, respectively $(\mathrm{p}<0.01)$.

The largest differences in charges between the 2 cohorts pertained to operating room time (MIS $=\$ 202,621.51$, Open $=\$ 253,014.41, \mathrm{p}=0.01)$. Additional cost savings for the MIS cohort were due to significantly lower mean charges for the use of blood products, cardiac ancillary 
TABLE 2. Comparison of pre- and postoperative radiographic measurements

\begin{tabular}{|c|c|c|c|c|c|c|c|}
\hline \multirow[b]{2}{*}{ Radiographic Measurement } & \multicolumn{3}{|c|}{ MIS } & \multicolumn{3}{|c|}{ Open } & \multirow{2}{*}{$\begin{array}{c}p \\
\text { value }\end{array}$} \\
\hline & Mean & SD & No. of Pts & Mean & SD & No. of Pts & \\
\hline \multicolumn{8}{|l|}{ Preop } \\
\hline Lumbar Cobb $\left({ }^{\circ}\right)$ & 27.10 & 8.26 & 36 & 37.91 & 11.61 & 32 & $<0.01$ \\
\hline SVA (mm) & 63.47 & 72.42 & 34 & 71.36 & 47.27 & 32 & 0.60 \\
\hline Lumbar lordosis $\left({ }^{\circ}\right)$ & 31.04 & 13.76 & 34 & 30.89 & 17.38 & 32 & 0.97 \\
\hline Pelvic incidence $\left({ }^{\circ}\right)$ & 50.81 & 10.76 & 35 & 57.69 & 10.59 & 32 & 0.01 \\
\hline Pelvic tilt $\left({ }^{\circ}\right)$ & 25.90 & 8.59 & 35 & 29.63 & 6.64 & 32 & 0.05 \\
\hline PI-LL $\left({ }^{\circ}\right)$ & 19.00 & 12.98 & 35 & 26.77 & 15.62 & 32 & 0.03 \\
\hline UIV/UIV+2 $\left(^{\circ}\right)$ & 8.27 & 4.94 & 30 & 6.34 & 5.03 & 31 & 0.14 \\
\hline \multicolumn{8}{|l|}{ Most recent } \\
\hline Lumbar Cobb $\left({ }^{\circ}\right)$ & 8.76 & 4.49 & 33 & 14.62 & 8.89 & 32 & $<0.01$ \\
\hline SVA (mm) & 51.17 & 48.90 & 35 & 28.17 & 37.69 & 32 & 0.03 \\
\hline Lumbar lordosis $\left({ }^{\circ}\right)$ & 35.32 & 13.21 & 35 & 53.50 & 13.59 & 32 & $<0.01$ \\
\hline Pelvic incidence $\left({ }^{\circ}\right)$ & 53.57 & 11.20 & 34 & 57.47 & 10.84 & 32 & 0.16 \\
\hline Pelvic tilt $\left({ }^{\circ}\right)$ & 27.50 & 8.61 & 34 & 27.86 & 10.17 & 32 & 0.88 \\
\hline PI-LL $\left({ }^{\circ}\right)$ & 16.25 & 16.70 & 36 & 3.26 & 11.89 & 31 & $<0.01$ \\
\hline UIV/UIV+2 $\left(^{\circ}\right)$ & 9.96 & 7.52 & 33 & 20.73 & 9.67 & 31 & $<0.01$ \\
\hline \multicolumn{8}{|l|}{ Net change (most recent vs preop) } \\
\hline Lumbar Cobb $\left(^{\circ}\right)$ & -17.81 & 7.01 & 33 & -23.28 & 9.05 & 32 & 0.01 \\
\hline SVA (mm) & -11.97 & 77.51 & 34 & -43.19 & 46.92 & 32 & 0.05 \\
\hline Lumbar lordosis $\left({ }^{\circ}\right)$ & 4.78 & 16.71 & 34 & 22.62 & 17.81 & 32 & $<0.01$ \\
\hline Pelvic incidence $\left({ }^{\circ}\right)$ & 4.09 & 15.74 & 34 & -0.22 & 6.63 & 32 & 0.15 \\
\hline Pelvic tilt $\left({ }^{\circ}\right)$ & 2.20 & 10.68 & 34 & -1.78 & 8.45 & 32 & 0.10 \\
\hline PI-LL $\left(^{\circ}\right)$ & -2.34 & 17.87 & 35 & -23.54 & 17.22 & 31 & $<0.01$ \\
\hline UIVIUIV+2 $\left(^{\circ}\right)$ & 2.16 & 7.51 & 29 & 14.42 & 10.21 & 31 & $<0.01$ \\
\hline
\end{tabular}

UIV = upper instrumented vertebrae.

services, imaging, laboratory tests, surgery costs, pharmacy, and routine nursing costs (Table 3 ). The MIS cohort had lower charges for respiratory services, although this savings was not statistically significant. Whereas the MIS cohort was noted to have decreased mean outpatient rehabilitation charges in most categories compared with the Open cohort, these savings were not statistically significant.

\section{Hospital Course and Complications}

Total length of hospital stay, defined as the initial surgery and any revision surgeries, was significantly less for the MIS cohort compared with the Open cohort (7.03 days vs 14.88 days, $\mathrm{p}<0.01)$. Patients who received outpatient rehabilitation experienced similar lengths of stay at the outpatient rehabilitation center (Table 3). Average total blood loss for the MIS and Open cohorts was 470.26 $\mathrm{ml}$ and $2872.73 \mathrm{ml}$, respectively ( $\mathrm{p}<0.01$ ) (Fig. 3). Complications noted during the patients' hospital course and follow-up are summarized in Table 4. In the Open cohort, 6 patients experienced dural tears, 4 patients were noted to have surgical-site infections, 4 patients experienced DVT, and 6 patients experienced postoperative ileus. No patients in the MIS cohort were noted to have dural tears, DVTs, surgical-site infections, or postoperative ileus. Dur- ing follow-up, 4 patients in the Open cohort experienced rod fractures and 3 patients in the MIS cohort were noted to have displaced grafts. A total of 7 patients needed 10 revision surgeries in the MIS cohort compared with only 5 patients in the Open cohort. The revision surgeries for the MIS cohort were performed to address cage migrations, pseudoarthrosis, removal of 1 patient's fractured pedicle screw with subsequent foraminotomy, TLIF for persistent pain, and foraminotomy for the treatment of radiculopathy. The revision surgeries for the Open cohort addressed rod fractures and pseudoarthrosis.

\section{Subset Analysis}

A subset of 8 patients who presented with preoperative SVA $<50 \mathrm{~mm}$, at most 2 comorbidities, and who were younger than 70 years of age experienced similar reductions in ODI score with both MIS and Open approaches (Table 5). Patients in this subset who received MIS correction had lower total charges, although this result did not reach statistical significance.

\section{Discussion}

In this retrospective study, we highlighted the possibility of minimizing costs associated with treating adult de- 


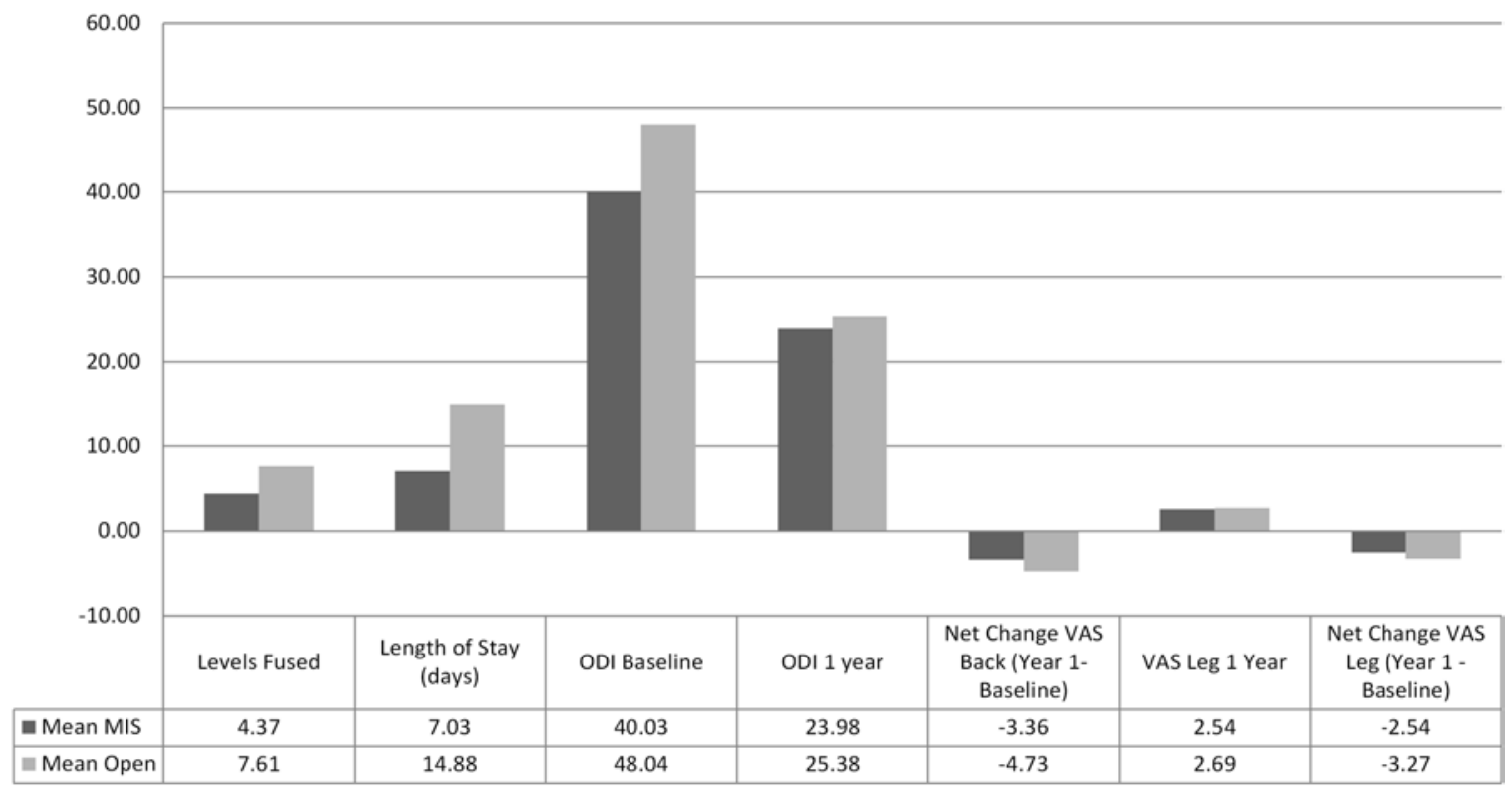

FIG. 1. Differences in clinical outcomes between the MIS and Open cohorts. All differences except ODI score at 1-year follow-up are statistically significant.

generative scoliosis using minimally invasive techniques. Our study analyzed data on billed hospital and outpatient rehabilitation charges and functional outcomes for patients who underwent surgical correction of their adult degenerative scoliosis through either an MIS or open-surgery approach. This study of 71 patients $(n=38$, MIS cohort; $\mathrm{n}=33$, Open cohort) demonstrated reduced costs, blood loss, and perioperative complications with the MIS cohort. The Open cohort experienced greater correction of SVA, more improvement in VAS back pain scores, and reduced need for revision surgery.

Correction by MIS of adult degenerative scoliosis was associated with an average savings of $\$ 122,081.71$ in inpatient hospital costs in comparison with open surgery. This trend was conserved with adjustment for inflation (Table 3). The largest contributions to the cost savings were related to operating room time, use of blood products, medications, length of hospital stay, and use of laboratory services. On average, mean operating room charges were lower by $\$ 50,392.90$ for the MIS cohort compared with the Open cohort. This may be related to decreased operating room time and the lower number of fused levels in the MIS group. This cost difference demonstrates that even with increased cost of instrumentation, MIS was

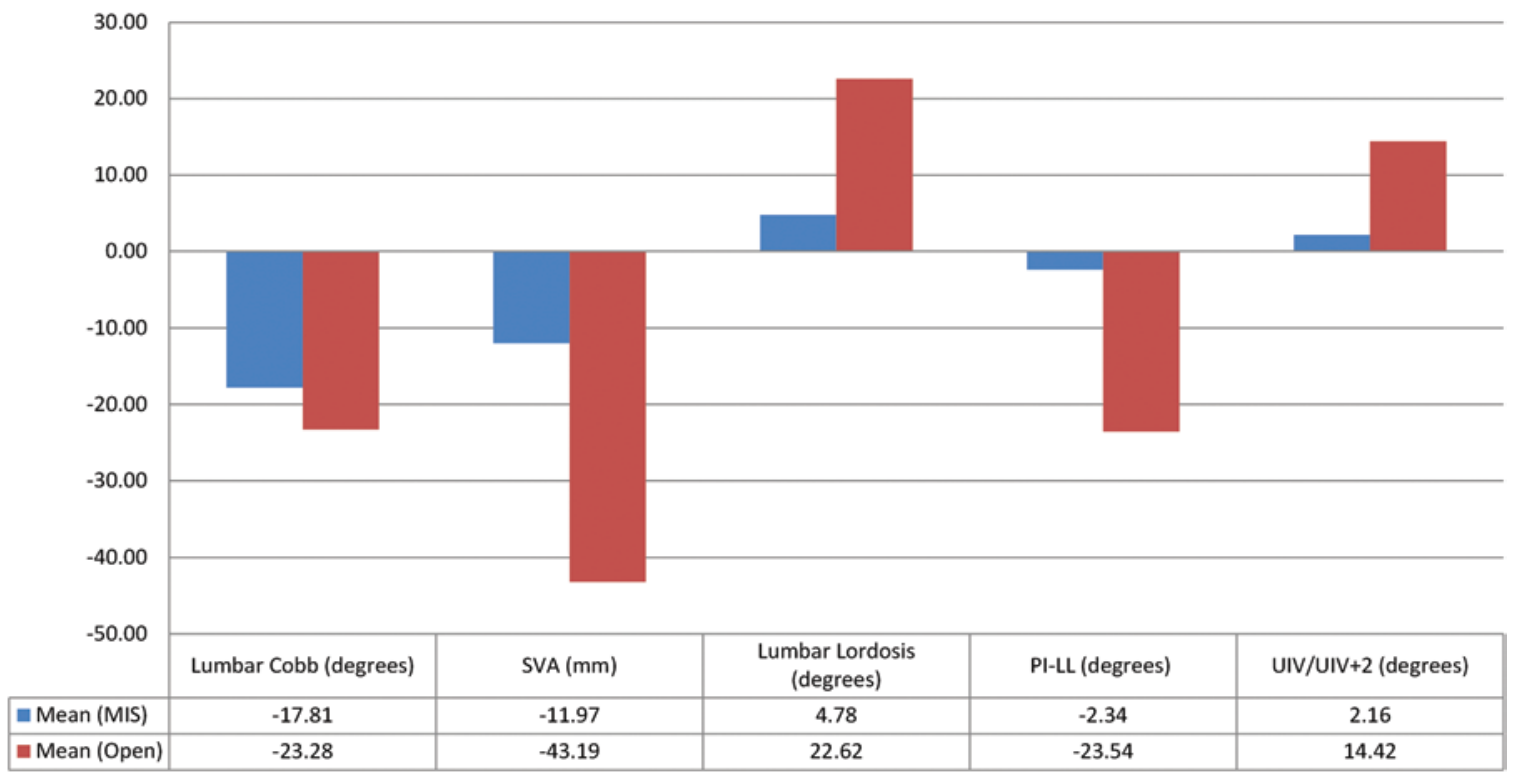

FIG. 2. Statistically significant differences in net change of radiographic parameters between patients in the MIS and Open cohorts. Figure is available in color online only. 
TABLE 3. Comparison of inpatient hospital, outpatient rehabilitation, and total charges

\begin{tabular}{|c|c|c|c|c|c|c|c|c|}
\hline \multirow[b]{2}{*}{ Type of Charge } & \multicolumn{3}{|c|}{ MIS } & \multicolumn{3}{|c|}{ Open } & \multirow{2}{*}{$\begin{array}{l}\text { Difference } \\
\text { Between } \\
\text { MIS \& Open }\end{array}$} & \multirow[b]{2}{*}{$\begin{array}{c}\mathrm{p} \\
\text { Value }\end{array}$} \\
\hline & Mean & SD & $\begin{array}{l}\text { No. of } \\
\text { Pts }\end{array}$ & Mean & SD & $\begin{array}{l}\text { No. of } \\
\text { Pts }\end{array}$ & & \\
\hline \multicolumn{9}{|l|}{ Inpatient charges } \\
\hline Length of hospital stay (days) & 7.03 & 3.86 & 38 & 14.88 & 8.20 & 33 & -7.85 & $<0.01$ \\
\hline Blood & $\$ 2539.11$ & $\$ 3886.10$ & 37 & $\$ 14,470.30$ & $\$ 9496.52$ & 33 & $-\$ 11,931.20$ & $<0.01$ \\
\hline Cardiac ancillary services & $\$ 2069.44$ & $\$ 2020.39$ & 25 & $\$ 4539.78$ & $\$ 2627.56$ & 31 & $-\$ 2470.34$ & $<0.01$ \\
\hline ICU nursing & $\$ 12,757.00$ & $\$ 14,549.51$ & 20 & $\$ 14,539.88$ & $\$ 11,707.66$ & 33 & $-\$ 1782.88$ & 0.64 \\
\hline Imaging & $\$ 9136.92$ & $\$ 7355.76$ & 38 & $\$ 14,031.89$ & $\$ 8552.72$ & 33 & $-\$ 4894.97$ & 0.01 \\
\hline Laboratory tests & $\$ 7173.54$ & $\$ 6196.78$ & 35 & $\$ 18,633.53$ & $\$ 9573.61$ & 33 & $-\$ 11,459.99$ & $<0.01$ \\
\hline Operating room & $\$ 202,621.51$ & $\$ 84,305.64$ & 38 & $\$ 253,014.41$ & $\$ 70,991.72$ & 33 & $-\$ 50,392.90$ & 0.01 \\
\hline Pharmacy & $\$ 4324.87$ & $\$ 3517.43$ & 38 & $\$ 12,684.44$ & $\$ 9934.44$ & 33 & $-\$ 8359.57$ & $<0.01$ \\
\hline Respiratory services & $\$ 6720.27$ & $\$ 15,090.07$ & 30 & $\$ 12,931.96$ & $\$ 9571.11$ & 33 & $-\$ 6211.69$ & 0.06 \\
\hline Routine nursing & $\$ 10,730.32$ & $\$ 5323.45$ & 38 & $\$ 18,398.85$ & $\$ 10,293.84$ & 33 & $-\$ 7668.53$ & $<0.01$ \\
\hline $\begin{array}{l}\text { Miscellaneous (nuclear medi- } \\
\text { cine, gastrointestinal, other) }\end{array}$ & $\$ 20,533.07$ & $\$ 11,416.01$ & 38 & $\$ 28,919.16$ & $\$ 11,385.71$ & 33 & $-\$ 8386.09$ & $<0.01$ \\
\hline Inpatient total & $\$ 269,807.35$ & $\$ 116,498.84$ & 38 & $\$ 391,889.05$ & $\$ 121,191.71$ & 33 & $-\$ 122,081.71$ & $<0.01$ \\
\hline Inpatient total (adjusted for inflation) & $\$ 292,329.91$ & $\$ 128,590.45$ & 38 & $\$ 433,620.37$ & $\$ 129,553.86$ & 33 & $-\$ 141,290.46$ & $<0.01$ \\
\hline \multicolumn{9}{|l|}{ Outpatient rehabilitation charges } \\
\hline Length of stay (days) & 13.94 & 7.38 & 16 & 16.36 & 10.62 & 14 & -2.42 & 0.48 \\
\hline Continuous assessment & $\$ 1583.38$ & $\$ 1172.66$ & 8 & $\$ 1070.01$ & $\$ 750.01$ & 8 & $\$ 513.37$ & 0.31 \\
\hline Microbiology & $\$ 184.20$ & $\$ 105.88$ & 10 & $\$ 654.40$ & $\$ 621.32$ & 5 & $-\$ 470.20$ & 0.12 \\
\hline Psychiatry & $\$ 783.84$ & $\$ 440.00$ & 11 & $\$ 851.06$ & $\$ 661.09$ & 9 & $-\$ 67.23$ & 0.80 \\
\hline Supplies & $\$ 229.18$ & $\$ 284.58$ & 14 & $\$ 224.84$ & $\$ 191.45$ & 13 & $\$ 4.34$ & 0.96 \\
\hline Pharmacy & $\$ 5422.36$ & $\$ 3254.84$ & 16 & $\$ 8691.12$ & $\$ 8389.71$ & 14 & $-\$ 3268.76$ & 0.18 \\
\hline Room and board & $\$ 13,892.50$ & $\$ 7,684.27$ & 16 & $\$ 15,801.64$ & $\$ 10,255.24$ & 14 & $-\$ 1,909.14$ & 0.57 \\
\hline Evaluation and management & $\$ 2808.94$ & $\$ 1300.56$ & 16 & $\$ 3038.86$ & $\$ 1893.07$ & 14 & $-\$ 229.92$ & 0.71 \\
\hline Physical therapy & $\$ 6471.19$ & $\$ 3509.06$ & 16 & $\$ 7182.86$ & $\$ 5806.83$ & 14 & $-\$ 711.67$ & 0.69 \\
\hline Occupational therapy & $\$ 5574.88$ & $\$ 2991.85$ & 16 & $\$ 6603.57$ & $\$ 5768.45$ & 14 & $-\$ 1028.70$ & 0.55 \\
\hline General laboratory & $\$ 2463.63$ & $\$ 1752.57$ & 16 & $\$ 2908.64$ & $\$ 2406.49$ & 14 & $-\$ 445.02$ & 0.57 \\
\hline Laboratory, nonurine & $\$ 110.94$ & $\$ 83.73$ & 16 & $\$ 124.29$ & $\$ 107.77$ & 14 & $-\$ 13.35$ & 0.71 \\
\hline Miscellaneous & $\$ 2681.50$ & $\$ 3641.11$ & 16 & $\$ 3320.22$ & $\$ 3599.57$ & 14 & $-\$ 638.72$ & 0.63 \\
\hline Outpatient rehabilitation total & $\$ 41,072.16$ & $\$ 22,541.03$ & 16 & $\$ 49,272.24$ & $\$ 36,991.91$ & 14 & $-\$ 8200.08$ & 0.48 \\
\hline Grand total & $\$ 353,322.66$ & $\$ 112,092.08$ & 16 & $\$ 493,614.64$ & $\$ 152,207.65$ & 14 & $-\$ 140,291.98$ & 0.01 \\
\hline Grand total (adjusted for inflation) & $\$ 380,732.69$ & $\$ 124,332.93$ & 16 & $\$ 539,331.69$ & $\$ 165,845.01$ & 14 & $-\$ 158,598.99$ & 0.01 \\
\hline
\end{tabular}

associated with cost savings. Minimizing the number of levels fused is an important aspect of MIS in obtaining similar correction while preventing additional devascularization and denervation of adjacent spinal levels. Additionally, patients in the Open cohort were more likely to receive placement and postoperative removal of inferior vena cava umbrellas, and this incurred additional operating room costs. Operating room time can also be influenced by individual surgeon experience and use of house staff. Patients in the MIS cohort received fewer blood products during surgery, leading to an average savings of $\$ 11,931.20$. Decreased hospital stay was reflected in lower costs of nursing staff and room charges, and this contributed to $\$ 7668.53$ of savings for the MIS cohort. Decreased use of medications contributed to an average savings of $\$ 8359.57$ for the MIS cohort. Open-surgery patients used respiratory services peri- and postoperatively to a greater extent compared with MIS patients, although this difference was not statistically significant.

Of the 71 patients included in this study, only 30 received postoperative rehabilitation at an affiliated rehabilitation facility. The remaining patients received rehabilitation services at home. The costs for home care were not included in this study, and no significant differences in costs of rehabilitation were found between the 2 cohorts (Table 3). The largest contributor to the cost of rehabilitation pertained to room and board charges, physical therapy, and occupational therapy.

The net reduction of ODI score was similar in both cohorts after 1 year. However, the reduction of VAS back pain scores was greater in the Open cohort. At 2 years of follow-up, the ODI scores of MIS patients were larger, and this difference approached statistical significance. Opensurgery patients presented with larger baseline deformity 


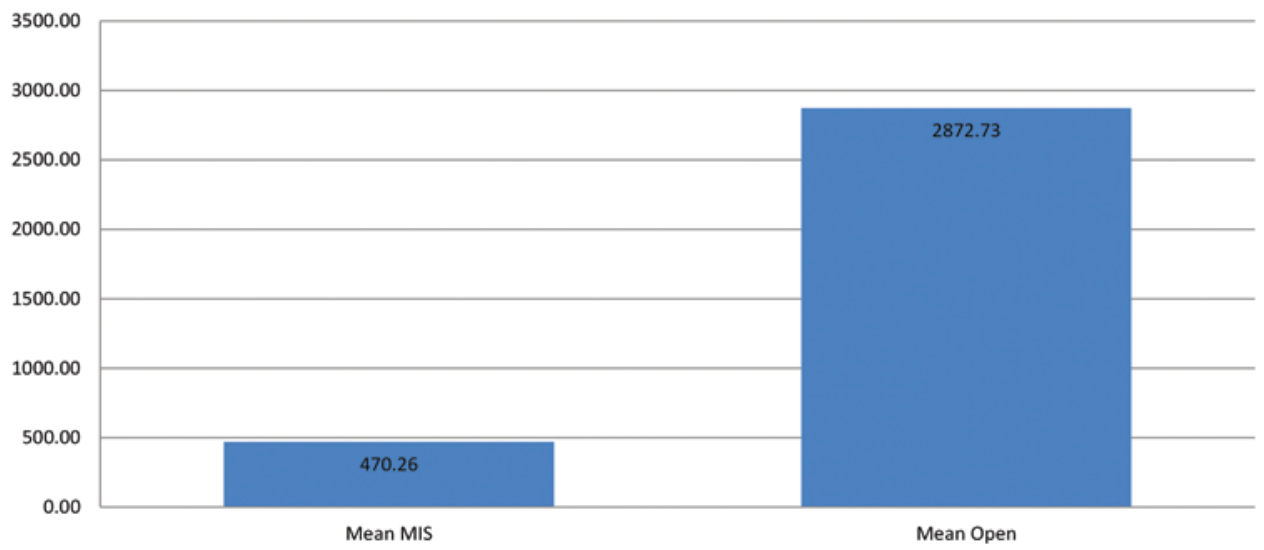

FIG. 3. Total EBL (in milliliters) for patients in the MIS and Open cohorts. Figure is available in color online only.

and on average received greater correction in measures such as SVA, PI-LL, and lumbar lordosis (Table 2). This may reflect the current lordotic rod-bending limitations in the MIS approach. These findings are consistent with the observations of the International Spine Study Group (ISSG) that less invasive surgery for treating ASD have limitations for scoliotic-curve correction for advanced curves. ${ }^{26}$ Overall, a minority of patients in each cohort experienced complications. Patients in the Open cohort experienced more dural tears and postoperative infections, while patients in the MIS cohort experienced greater postoperative radiating pain and need for revision surgery.

This study is the first to compare the costs of MIS and open surgery for the treatment of adult degenerative scoliosis. Its findings are consistent with current literature comparing MIS and open surgery for 1- and 2-level fusions. Lucio et al. reported a $10.4 \%$ savings associated with MIS for 2-level, instrumented LIF, and Wang et al. observed average savings of $\$ 8285$ and $\$ 21,389$ for 1- and 2-level MIS posterior interbody fusion procedures, respectively. ${ }^{12,23}$ A comparison of perioperative costs and outcomes for patients undergoing MIS versus Open TLIF demonstrated significant cost savings for MIS procedures, with similar immediate outcomes. ${ }^{19}$ Furthermore, in a large, multicenter retrospective analysis conducted by Wang et al., 2-level MIS fusion procedures were associated with an average savings of \$2106 in acute hospitalization costs and a reduction in mean length of hospital stay in comparison with open surgery. ${ }^{24}$ Our data are also consistent with findings of multiple studies in which the majority of MIS cost savings in comparison with open surgery are primarily related to length of hospital stay, blood loss, pharmacy, and laboratory costs. ${ }^{1,18,19,24}$

To date, studies have demonstrated efficacy in using MIS approaches to perform lumbar fusions. Numerous benefits have been associated with the MIS approach, including reductions in blood loss, wound infections, and length of hospital stay..$^{3,7,8,15,25}$ Dakwar et al. reported a mean improvement of 5.7 points for axial VAS pain scores, a $23 \%$ improvement in ODI scores, and a $19.9^{\circ}$ reduction in Cobb angle for patients who received treatment of adult degenerative scoliosis through a minimally invasive, lateral, retroperitoneal transpsoas approach. ${ }^{7}$ Furthermore, a review of long-term follow-up by Anand et al. has further demonstrated significant reduction in Cobb angle and sagittal balance associated with MIS correction of adult scoliosis. ${ }^{2}$ Our data are consistent with the findings of the ISSG, which compared MIS, Open, and Hybrid techniques for treating ASD. This comparison demonstrated increased SVA correction for the Open group but no significant differences in pre- and postoperative mean ODI and VAS scores at 1 year of follow-up. ${ }^{9}$

While numerous benefits have been associated with MIS techniques, there are several limitations to their use. In a study evaluating correction of thoracolumbar scoliosis, approximately one-third of patients did not experience improvement in sagittal balance without the use of osteotomies. ${ }^{7}$ Moreover, patients undergoing minimally invasive correction are still at risk for experiencing postoperative numbness, pain, dysesthesia, and paresthesia.,25 Although

TABLE 4. Complications noted in patients in the MIS and Open cohorts during follow-up

\begin{tabular}{lcc}
\hline \multicolumn{1}{c}{ Complication } & MIS & Open \\
\hline Dural tear & 0 & 6 \\
\hline DVT & 0 & 4 \\
\hline Superficial vein thrombosis & 0 & 2 \\
\hline Revision surgeries & 10 & 5 \\
\hline PJK & 1 & 1 \\
\hline Pseudarthrosis & 1 & 2 \\
\hline Rod fracture & 0 & 4 \\
\hline Unresolved paresthesia & 9 & 7 \\
\hline Radiating pain & 7 & 1 \\
\hline Migrated cage & 1 & 0 \\
\hline Displaced graft & 3 & 0 \\
\hline Adjacent-level disease & 0 & 1 \\
\hline Unresolved weakness & 0 & 2 \\
\hline Dysesthesia & 1 & 0 \\
\hline Surgical-site infection & 0 & 4 \\
\hline Postop infection (systemic) & 2 & 4 \\
\hline Postop ileus & 0 & 6 \\
\hline
\end{tabular}


TABLE 5. Subset analysis of patients with preoperative SVA $<50 \mathrm{~mm}$, age $<70$ years, and $\leq 2$ comorbidities

\begin{tabular}{|c|c|c|c|c|c|c|}
\hline Patient Data & Age (yrs) & Comorbidities & Preop Cobb $\left({ }^{\circ}\right)$ & Preop SVA (mm) & Net Change in ODI Score & Inpatient Cost (\$) \\
\hline \multicolumn{7}{|l|}{ Open, $n=4$} \\
\hline Case 1 & 58.56 & 2.00 & 36.10 & 0.00 & -2.00 & $430,722.00$ \\
\hline Case 2 & 67.64 & 1.00 & 28.50 & 25.00 & -38.00 & $147,405.70$ \\
\hline Case 3 & 67.11 & 1.00 & 40.70 & 0.00 & -34.00 & $382,773.25$ \\
\hline Case 4 & 63.68 & 1.00 & 53.00 & 18.00 & -1.00 & $425,372.27$ \\
\hline Mean Open & 64.25 & 1.25 & 39.58 & 10.75 & -18.75 & $346,568.31$ \\
\hline SD & 4.18 & 0.50 & 10.27 & 12.74 & 19.99 & $134,497.15$ \\
\hline \multicolumn{7}{|l|}{ MIS, $n=4$} \\
\hline Case 1 & 57.05 & 2.00 & 35.80 & 8.00 & -44.00 & $283,805.90$ \\
\hline Case 2 & 52.85 & 1.00 & 22.40 & 30.00 & -25.00 & $207,364.70$ \\
\hline Case 3 & 60.85 & 0.00 & 33.50 & 14.00 & -8.00 & $174,266.85$ \\
\hline Case 4 & 60.08 & 0.00 & 23.00 & 28.00 & -6.00 & $203,550.35$ \\
\hline Mean MIS & 57.71 & 0.75 & 28.68 & 20.00 & -20.75 & $217,246.95$ \\
\hline SD & 3.63 & 0.96 & 6.97 & 10.71 & 17.69 & $46,771.21$ \\
\hline
\end{tabular}

$\mathrm{n}=$ number of patients.

rod fractures have not been a significant concern, hardware complications, including misplaced screws and cage migrations, have been reported. ${ }^{8}$

The MIS approach may minimize costs for a select subset of patients with less severe preoperative SVA but be less effective for patients with more severe disease. Mummaneni et al. developed a 6-level treatment algorithm ("MiSLAT") to guide spinal surgeons in the use of MIS for the treatment of degenerative deformity. They suggested that MIS treatment is recommended for Level I-IV deformities, whereas open approaches are recommended for Level V and VI deformities. ${ }^{14}$ As new techniques are developed, MIS procedures may have the potential to attain improved radiographic and functional outcomes and provide cost-minimization benefits for patients with a need for significant deformity correction.

Our study has several important limitations. This study was designed as a cost-minimization analysis, primarily evaluating reduction of costs in the presence of similar functional outcomes. It did not evaluate change in life expectancy or measure quality-adjusted life-years in a manner to calculate incremental cost effectiveness. As a result, the findings of this study do not allow for conclusions regarding cost effectiveness of MIS over open-spine surgery. Another limitation is that billed charges do not perfectly measure either cost or payments, and the absolute value of charges may be inflated. This may potentially under- or overestimate the true cost to society associated with MIS and open surgery. However, the trends observed in charge data may serve as a proxy for cost differences between patients who undergo MIS versus open surgery. ${ }^{13}$ The use of billed charges may not account for differences in hospital-fee schedules, but every patient in this study was treated within the same timeframe and in the same hospital, eliminating the need to adjust for different billing practices for each cohort. Although this study oc- curred over 6 years, adjustment of total inpatient costs for inflation yielded similar differences in costs between the 2 cohorts. Another limitation of this study is that patients in the Open cohort presented with greater baseline deformity, and this decreased the level of matching between cohorts. In our subset analysis of 8 patients with similar characteristics, we found similar reduction in ODI scores and decreased costs associated with MIS, although this difference was not statistically significant. Our follow-up data were limited because we compared ODI scores for 52 of 71 patients after 1 year and 37 patients after 2 years, representing significant loss of follow-up. This may result in a selection bias toward patients with more severe disease and suboptimal outcomes.

\section{Conclusions}

Minimally invasive surgery demonstrated reduced costs, blood loss, and length of hospital stay, whereas open surgery exhibited greater improvement in VAS scores, deformity correction, and sagittal balance. Additional studies with more patients and longer follow-up will determine if MIS presents cost-minimization benefits for certain subsets of patients with adult degenerative scoliosis.

\section{Acknowledgments}

We thank Dr. Stephen Ondra, Ms. Jessica Drope, Ms. Sara Thompson, and Mr. Ross York-Erwin for their contributions to this study.

\section{References}

1. Allen RT, Garfin SR: The economics of minimally invasive spine surgery: the value perspective. Spine (Phila Pa 1976) 35 (26 Suppl):S375-S382, 2010

2. Anand N, Baron EM, Khandehroo B, Kahwaty S: Long-term 2- to 5-year clinical and functional outcomes of minimally 
invasive surgery for adult scoliosis. Spine (Phila Pa 1976) 38:1566-1575, 2013

3. Anand N, Baron EM, Thaiyananthan G, Khalsa K, Goldstein TB: Minimally invasive multilevel percutaneous correction and fusion for adult lumbar degenerative scoliosis: a technique and feasibility study. J Spinal Disord Tech 21:459467, 2008

4. Bess S, Boachie-Adjei O, Burton D, Cunningham M, Shaffrey C, Shelokov A, et al: Pain and disability determine treatment modality for older patients with adult scoliosis, while deformity guides treatment for younger patients. Spine (Phila Pa 1976) 34:2186-2190, 2009

5. Carreon LY, Puno RM, Dimar JR II, Glassman SD, Johnson JR: Perioperative complications of posterior lumbar decompression and arthrodesis in older adults. J Bone Joint Surg Am 85-A:2089-2092, 2003

6. Carter OD, Haynes SG: Prevalence rates for scoliosis in US adults: results from the first National Health and Nutrition Examination Survey. Int J Epidemiol 16:537-544, 1987

7. Dakwar E, Cardona RF, Smith DA, Uribe JS: Early outcomes and safety of the minimally invasive, lateral retroperitoneal transpsoas approach for adult degenerative scoliosis. Neurosurg Focus 28(3):E8, 2010

8. Dhall SS, Wang MY, Mummaneni PV: Clinical and radiographic comparison of mini-open transforaminal lumbar interbody fusion with open transforaminal lumbar interbody fusion in 42 patients with long-term follow-up. J Neurosurg Spine 9:560-565, 2008

9. Haque RM, Mundis GM Jr, Ahmed Y, El Ahmadieh TY, Wang MY, Mummaneni PV, et al: Comparison of radiographic results after minimally invasive, hybrid, and open surgery for adult spinal deformity: a multicenter study of 184 patients. Neurosurg Focus 36(5):E13, 2014

10. Isaacs RE, Podichetty VK, Santiago P, Sandhu FA, Spears J, Kelly K, et al: Minimally invasive microendoscopy-assisted transforaminal lumbar interbody fusion with instrumentation. J Neurosurg Spine 3:98-105, 2005

11. Kim YB, Lenke LG, Kim YJ, Kim YW, Blanke K, Stobbs G, et al: The morbidity of an anterior thoracolumbar approach: adult spinal deformity patients with greater than five-year follow-up. Spine (Phila Pa 1976) 34:822-826, 2009

12. Lucio JC, Vanconia RB, Deluzio KJ, Lehmen JA, Rodgers JA, Rodgers W: Economics of less invasive spinal surgery: an analysis of hospital cost differences between open and minimally invasive instrumented spinal fusion procedures during the perioperative period. Risk Manag Healthc Policy 5:65-74, 2012

13. McCarthy I, Hostin R, O'Brien M, Saigal R, Ames CP: Health economic analysis of adult deformity surgery. Neurosurg Clin N Am 24:293-304, 2013

14. Mummaneni PV, Tu TH, Ziewacz JE, Akinbo OC, Deviren V, Mundis GM: The role of minimally invasive techniques in the treatment of adult spinal deformity. Neurosurg Clin $\mathbf{N}$ Am 24:231-248, 2013

15. Mundis GM, Akbarnia BA, Phillips FM: Adult deformity correction through minimally invasive lateral approach techniques. Spine (Phila Pa 1976) 35 (26 Suppl):S312-S321, 2010

16. Okuda S, Miyauchi A, Oda T, Haku T, Yamamoto T, Iwasaki M: Surgical complications of posterior lumbar interbody fusion with total facetectomy in 251 patients. J Neurosurg Spine 4:304-309, 2006

17. Park P, Foley KT: Minimally invasive transforaminal lumbar interbody fusion with reduction of spondylolisthesis: technique and outcomes after a minimum of 2 years' follow-up. Neurosurg Focus 25(2):E16, 2008

18. Parker SL, Adogwa O, Bydon A, Cheng J, McGirt MJ: Costeffectiveness of minimally invasive versus open transforaminal lumbar interbody fusion for degenerative spondylolisthe- sis associated low-back and leg pain over two years. World Neurosurg 78:178-184, 2012

19. Pelton MA, Phillips FM, Singh K: A comparison of perioperative costs and outcomes in patients with and without workers' compensation claims treated with minimally invasive or open transforaminal lumbar interbody fusion. Spine (Phila Pa 1976) 37:1914-1919, 2012

20. Schwab F, Dubey A, Gamez L, El Fegoun AB, Hwang K, Pagala M, et al: Adult scoliosis: prevalence, SF-36, and nutritional parameters in an elderly volunteer population. Spine (Phila Pa 1976) 30:1082-1085, 2005

21. Smith JS, Shaffrey CI, Glassman SD, Berven SH, Schwab FJ, Hamill CL, et al: Risk-benefit assessment of surgery for adult scoliosis: an analysis based on patient age. Spine (Phila Pa 1976) 36:817-824, 2011

22. Tribus CB: Degenerative lumbar scoliosis: evaluation and management. J Am Acad Orthop Surg 11:174-183, 2003

23. Wang MY, Cummock MD, Yu Y, Trivedi RA: An analysis of the differences in the acute hospitalization charges following minimally invasive versus open posterior lumbar interbody fusion. J Neurosurg Spine 12:694-699, 2010

24. Wang MY, Lerner J, Lesko J, McGirt MJ: Acute hospital costs after minimally invasive versus open lumbar interbody fusion: data from a US national database with 6106 patients. J Spinal Disord Tech 25:324-328, 2012

25. Wang MY, Mummaneni PV: Minimally invasive surgery for thoracolumbar spinal deformity: initial clinical experience with clinical and radiographic outcomes. Neurosurg Focus 28(3):E9, 2010

26. Wang MY, Mummaneni PV, Fu KM, Anand N, Okonkwo DO, Kanter AS, et al: Less invasive surgery for treating adult spinal deformities: ceiling effects for deformity correction with 3 different techniques. Neurosurg Focus 36(5):E12, 2014

\section{Disclosure}

Dr. Fessler is an owner of In Queue Innovations and a consultant for DePuy-Synthes. He also holds patents for DePuy-Synthes, Stryker, and Medtronic. Dr. Koski is a consultant for NuVasive, Medtronic, and Spinewave. He is also a direct owner of stock in NuVasive.

\section{Supplemental Information \\ Proceedings}

Portions of this work were presented at the 30th Annual Meeting of the AANS/CNS Section on Disorders of the Spine and Peripheral Nerves, Orlando, Florida, March 5-8, 2014.

\section{Author Contributions}

Conception and design: Fessler, Uddin, Haque, Koski. Acquisition of data: Uddin, Haque, Sugrue, Ahmed, Press. Analysis and interpretation of data: Fessler, Uddin, Haque, Sugrue, Koski. Drafting the article: Fessler, Uddin, Haque, Ahmed, El Ahmadieh. Critically revising the article: Fessler, Uddin, Haque, El Ahmadieh, Koski. Reviewed submitted version of manuscript: all authors. Approved the final version of the manuscript on behalf of all authors: Fessler. Statistical analysis: Uddin. Administrative/technical/material support: Uddin, Press. Study supervision: Fessler, Haque, Koski. Performed all surgeries for the minimally invasive surgery cohort: Fessler. Performed all surgeries for the open cohort: Koski.

\section{Correspondence}

Richard G. Fessler, University Neurosurgery, Rush University Medical Center, 1725 W. Harrison St., Ste. 855, Chicago, IL 60612. email: RFessler@rush.edu. 